\title{
Study on the Ways of Cultivating Information Design Consciousness in Visual Communication Design Education
}

\author{
Chen Jia \\ Hong Sheng Lu China Chongqing Nan'an District 35 Building No.1 32-9 \\ 3904458@qq.com
}

Keywords: Visual Communication Design, Art Education, Design Consciousness

\begin{abstract}
Visual communication design education habits and traditional professional self-positioning, in the new technical environment and practice platform environment, faced with the challenge of adaptability, while the new concept of education and professional ideas put forward, so that visual communication design itself challenges in the professional knowledge system. Visual communication design education perspective should be maintained in the traditional visual expression as the main design expression at the same time, give full consideration to the design of art disciplines of knowledge cross characteristics, the design object from the visual art of perception education, widening for the realization of the purpose of the design : through the visual expression and transmission design to achieve effective energy dissemination, in the professional education to educate students to convey the consciousness of information design awareness, so that students realize that the effective transmission of information is the visual design of the pursuit of the goal.
\end{abstract}

\section{Introduction}

Artistic Perceived Education is one of the core of the design art education. When students face the design of large information, the existence of the pursuit of visual design in the form of existence, while ignoring the thinking: why is the design, the visual communication design methods and methods, and visual communication design objectives of awareness, there is a certain degree of logical confusion. In the professional course of visual communication, the demand for art-based education and the educational needs of the design goal are coexistent. The design object must have the consciousness of information design, and the works of the audience will be accepted.

Information design awareness refers to the design process, the design of the subject matter involved in the information, active and conscious of a clear understanding, evaluation and organization, making the design of the information display more profound and accurate, through the design of the transmission information is more useful. Training information design awareness, the main goal is to make the information more reasonable display to the audience, as the design process of a self-habit, so that students realize that the design process in the delivery, but also to the audience to bring an experience, the experience is more conducive to the good transmission and communication of information. Design of art in the habit of cognition, including visual communication design, environmental art design and many other sub-areas, visual communication design is a way of information transmission design, but also to express and display the main design art, over the years Has never been a positive view from the information point of view of visual communication design, but has been on the visual communication design of the information perspective of thinking and exploration, such as information quality training on the discussion. The idea of introducing the information in the design art should be based on the art-oriented thinking, that is, the design object itself is a kind of information and the design is about how to achieve the performance of information transmission design. 


\section{Visual Communication Design of Professional Courses in the Design of Information Design Awareness after the Lack of Training Problems}

The ultimate goal of visual communication design is to convey information to the audience, rather than the visual itself, in the delivery process, the delivery of the way to design, but the delivery of the design cannot interfere with or affect the transmission of works of information. Visual communication cannot be simply understood as the design of the visual, but also should be understood as the visual as the existence and delivery of the form of information transmission design, focusing on the delivery of the design at the same time, we must also pursue the work of the overall information transfer design. At present, in the visual communication design profession, all kinds of professional courses, are more emphasis on the art of design perception, which is the design of education in the practice of doubt, but the design is for the audience, the audience in addition to the design works of artistic feelings the pursuit of the outside, but also on the work of the body also has a cognitive internal logic needs, in addition to the works in addition to the good sense of art, but also the work itself should be given the function of the smooth realization of the protection. The design of the design art should always adhere to the principle of functional decision form, to practice the design of art and visual design goal is to guide the audience to find their own needs and goals to achieve the goal. In the professional visual communication design of professional courses, the pursuit of various types of visual effects and often become the only goal to guide students to create, can not be denied the more close to the art of creative courses, such as graphic illustrations creation class, there is a strong demand for the existence of art, but the design itself is a certain kind of activities for the purpose of the audience service, information design consciousness itself is based on a certain logical thinking on the basis of traditional art education in the image of thinking There are habits of cognitive differences, visual communication design is not just a visual expression of a design, it should be visual and logical guidance under the information display.

The traditional visual communication design, in some education is characterized as a two-dimensional nature of the art and design, the typical cognitive bias that the visual communication design called the graphic design, and visual communication design in the design of basic courses, but also perceived the three-dimensional space visual is also an integral part of visual communication design, so in the design of basic courses and on the use of three-dimensional effect of basic education, visual is the core of the professional research field to convey the professional design of the object, any information through the visual way to convey can be regarded as the field of expertise to study and study; two-dimensional plane, three-dimensional space, animation and other specific visual information transmission methods can be visual communication design expression is the design can be used when the tool. Visual communication design is increasingly integrated into the design of integrated information transmission design, visual communication design should be understood as the visual field and aids in the field of all available methods of a comprehensive application of the current design methods and means of diversification, for the visual communication design more than the traditional tools of the richer performance of the tools and ways, but also faced with more challenges and needs, visual communication design method and the carrier has not only a link in printing, not just stay in newspapers, magazines, books And other traditional two-dimensional plane carrier, the new media technology involved, so that the audience had to visual design of the new requirements, to a large extent to improve the degree of visual communication design intervention. Visual communication to the purpose of communication for information, web pages, electronic magazines and other new visual form of the emergence of means that a greater number of information subject needs to design, if only to stay in the traditional carrier expression and application level, it is difficult to meet the audience of the new demand, can only be eliminated by the market. All auxiliary means of expression, as long as the benefit of the transmission of visual information, are the visual means of communication design. Web design, has been conscious of the order of the display of information on the site of the arrangement, that is, information architecture, which is designed to face the living environment of a adaptive performance, the previous visual communication design, this is not very troubled by this It is too 
obvious, so there has been no systematic purpose of the system to find a solution, but in the design level has been related to the exploration, such as visual process design, etc., in fact, is based on the audience how to obtain a search of information.

Visual communication design of the object itself is a body of information, whether it is graphics also, text, color or shape, are the carrier of information. Design objects are no longer limited to the design and performance of graphics, text design and arrangement, more of a pile of chaotic a lot of information for integrated design and display. After the human into the information society, the demand is no longer simply what kind of information transmission, but how in the massive information, the orderly needs of the audience information needs to be ordered and effective display, including graphics icon, multi-level text, graphics, color and other visual objects will also include the information display logic, display order and other invisible objects to design. Because the theory of visual understanding, people in the completion of an activity when the psychological needs or plans for reference, to help people organize information. The traditional visual communication design bias is used to express the use of graphics, but in the new environment, the design of the subject object can not be the same as before only single-dimensional information expression needs, the huge picture, the expression of the space environment is no longer loose, the communication design is faced with a substantial demand for new design basics. For the new design object, we need to consider the needs of the audience, under the auspices of information design, all the ways to improve the quality of visual information transmission utility services in the effective transmission of visual information this goal.

\section{Thinking on the Cultivation of Information Design Consciousness in Visual Communication Design}

For information, visual information is part of the existence of many forms of information; for visual communication design, information is the purpose of visual communication design. The core of visual communication design is the visual expression design, is a visual perception of the art of communication design, but also a commercial application of aesthetic principles. In the past, the visual communication design education, the main focus on training students' perception of art, the visual expression of the method of exploration and application, as well as the creative ability to innovate. In essence, the purpose of visual communication is to convey information, information is to convey the visual design to convey the main body, but also the audience to convey the purpose of visual design works. Based on a certain expression of the purpose of the information, the visual communication design to form a visual work, passed to the audience. This process must be faced with the problem of how to improve the effectiveness of information transmission in the process of transmission, and the previous education is often focused on how to visualize the information on the way to explore and innovate, while ignoring the information in the transmission process, the audience acceptance of information. The introduction of information design awareness can enhance the quality of information transmission to the visual communication, so that students in the learning and design process, consciously all the visual field of information to conduct an orderly design display to improve the entire design work in the information transmission utility.

Artistic design is the practice of abstract thinking and image thinking. It is a combination of rationality and sensibility. Artistic creativity is an important way to design the cognitive order of the audience. The characteristic of the design profession is to adhere to the art as the orientation. Artistic perception is the key ability that the design professional students need to cultivate. This is also the value of art education. The design art profession is a typical interdisciplinary field, and the difference between the traditional art class is that the design art is an applied art, any kind of design art that is inevitable and social production, manufacturing and service association, which is the art of human life in the field of penetration and expansion. In the traditional visual communication design professional teaching, there are often ways to emphasize the way of visual communication, that is, an emphasis on visual art perception, which for the total amount of information design tasks, the audience effective access to information will not cause a big impact, but for the general visual-based design display, educational display and other large flow of information object design, 
there will be a serious impact. Such as book design, guided system design and other categories, in the face of such complex information, we must find a way to organize information, so that information more orderly display to the audience, which requires an order, this order is Human cognitive logic. In the design of the use of logical cognitive law, you need to have a certain logical thinking ability, rather than just stay in the layout, illustrations, style and other aspects of exploration and design, the object should be designed ontology, object ontology information display order analysis.

\section{Conclusion}

The purpose of cultivating students' information design consciousness is to strengthen the goal-oriented and goal decision process of visual communication design. Visual communication design, transmission of information is the goal of visual communication, art design is to achieve the methods and ways to determine the effectiveness of information transmission to choose what kind of design methods, a direct impact on the effectiveness of information transmission, in the professional curriculum, the object ontology as a body of information, from the overall start, thinking about how to design information in order to more efficient use of information. Design art has its rational side, the art of art design, focusing on the basis of human cognitive logic on the basis of the organization of visual information and display of art and design ability, to gather the aesthetic experience of the audience experience and logical reasoning recognition of the dual Function realization.

\section{References}

[1] Wang Ke. Discussion of classical moire in the visual communication design of the application[J]. Drama House. 2017 (16)

[2] Li Bo. Analysis of visual communication design diversification and individualization[J]. Industrial design. 2017 (07)

[3] Xu Liwen, Zhang Ting. On the visual communication design of the impact of enterprises[J]. Economic Research Guide. 2017 (26)

[4] He MiaoMiao. New media art under the visual communication design [J]. News communication. 2017 (16)

[5] Chen Haipeng. Study on the talent cultivation mode of visual communication design professionals under the guidance of the spirit of the pioneers [J]. Popular Literature. 2017 (17) 